\title{
Essay: Individuals Providing Consultation on the Psychology of Sport within NCAA Division I Institutions
}

\author{
David Klossner \\ National Collegiate Athletic Association
}

This article is written in response to Bemiller and Wrisberg's (2011) review of National Collegiate Athletic Association (NCAA) policy and their recommendations for change pertaining to sports psychology consultants. The authors are generally concerned about potential limitations regarding on-field consultant access to student-athletes that could help in the development of the student-athletes' on- and off-field success. Even though institutions can hire individuals as sport coaches with sport psychology certifications and training within the current NCAA regulations, questions are raised about the threshold for an open-door policy that allows consultants access to student-athletes.

The following information is meant to serve as an overview of NCAA policy and resources on the topic. Questions on implementation of NCAA bylaws and interpretations should be directed to each athletics department's compliance staff as content may change due to the ever-evolving world of intercollegiate athletics.

The NCAA is a member association of approximately 1,300 four-year institutions of higher education and athletics conferences. Each year, more than 400,000 student-athletes compete in 23 sports at these NCAA member schools across three separate divisions. Among the core purposes of the Association is a commitment to govern athletics competitions in a fair, safe, equitable, and sportsmanlike manner and to integrate intercollegiate athletics into higher education so that the educational experience of the student-athlete is paramount.

As a member association, the NCAA has a committee structure comprised of university presidents and athletics staff members through which it proposes, discusses and approves rules and regulations. As discussed throughout the Bemiller and Wrisberg article, the authors report multiple reviews by the NCAA membership relative to the use of sport psychology consultants. Ultimately, these university staff members approve NCAA legislation and policy.

However, as noted throughout the article, the authors promote the position that a sport psychology consultant should have more access to student-athletes to help provide mental training for performance and provide assistance in the development of student-athletes' psychological skills at both on- and off-field settings.

Klossner is the director of health and safety, National Collegiate Athletic Association, Indianapolis, IN. 
From an on-field perspective, the NCAA regulations ${ }^{1}$ clearly state that any individual who participates in any manner in the coaching of a sport in practice, games or organized activities directly related to that sport must be counted as a coach as stipulated in the limitations for that sport. Some athletics staff may be classified as "non-coaching" and might be allowed at practice or sit on the bench of competitions as long as they are simply observing and not performing coaching activities ${ }^{2,3}$.

Actions of an individual interacting with the athletics department that resemble coach actions could include shagging balls, assisting with drills, throwing batting practice, signaling in plays, serving as a practice player, setting up offense and defense alignments, or walking out to the pitching mound for player consultation during a game. The current NCAA interpretations ${ }^{4,5}$ for sport psychologists allows practice attendance and student-athlete evaluation but only for the purposes of assisting the student-athlete in off-court or off-field non-coaching activities (e.g., mental imagery) directly related to the sport as long as the individual does not participate in any coaching activities. The current interpretation is an attempt to provide greater access for sports psychology consultants to be able to evaluate student-athletes and assist them off the field or court without having to be included in the coaching limits. Institutions certainly have the flexibility to decide whether or not their services are such that they should be employed as a countable coach.

The latest membership review and position on the use of non-coaching personnel in the Division I membership (NCAA, 2010) reiterated their position to ensure the sustainability of competitive equity across member institutions. In addition to maintaining competitive equity, the intent of the coaching limitations is to restrict the actual coaching of student-athletes to those individuals who are identified as coaches.

NCAA legislation is not intended to define the professional competency of a coach or any other staff position within an athletics department. Institutions certainly can hire an individual with sport psychology certifications and training as a sport coach to fit within the sport coach limitations. As Bemiller and Wrisberg's article refers to the interaction with intercollegiate athletics in a "consultant" role rather than a full-time coach position, institutions must follow NCAA regulations 6 for the use of consultants.

Considering the overlap between coaching and mental training these interpretations may be too liberal for individuals serving as consultants for mental training services and too limiting for clinicians licensed to practice psychology. However, these dual roles are at the core of the debate.

An NCAA News article in 2005 (Hosick, 2005) attempted to describe for the NCAA membership the complexity of the field of sport psychology for both performance enhancement and clinical psychological health. Since the term "sport psychology" is applied liberally to a vast field of professionals it is often difficult for those within the sports industry to understand whether they are working with someone who is licensed to practice psychology and can diagnose and treat mentalhealth problems, or someone trained to apply mental-preparation techniques to enhance athletic performance. These dual roles for a sport psychologist are often interrelated and can make enforcement of regulations for coaching interaction difficult to regulate. At times, this dual role raises concerns about patient confidentiality and could present barriers to engaging and treating a student-athlete. However, the 
benefits of observing and engaging an athlete in the moment for intervention can add value to the athlete medical model. These dual roles also bring to question the required qualifications for sport psychology consultants working with athletes as noted by the author's second recommendation.

The NCAA continues to address the psychological health of student-athletes and emphasizes the importance of having access to licensed mental health professionals for referrals and consultation (Harmon et. al. 2011; NCAA Sports Medicine Handbook, 2006; Thompson and Sherman, 2007). These professionals are often licensed to practice psychology, typically with a clinical or counseling psychology background; trained to identify, diagnose, treat mental-health problems; and have additional experience in athletics or with athletes. As noted by the authors, decrements in performance can often be due to underlying psychological issues and require clinical counseling to address the health of the student-athletes. This could carry over to improved performance on the field.

Ultimately, the university controls the hiring of professionals for both academics and athletics. It is the responsibility of each member institution to protect the health of and provide a safe environment for each of its participating studentathletes. The NCAA members will continue to discuss the landscape of coaching and student-athlete well-being retaining or modifying their rules and regulations based on membership input and support. Articles such as the one provided by Bemiller and Wrisberg add value to the discourse within the sports community.

\section{Notes}

1. NCAA Division I Bylaw 11.7.1.1.1 Countable Coach. An athletics department staff member must count against coaching limits as soon as the individual participates (in any manner) in the coaching of the intercollegiate team in practice, games or organized activities directly related to that sport, including any organized staff activity directly related to the sport.

2. NCAA Division I Bylaw 11.7.1.1.1.1 Noncoaching Activities. Institutional staff members involved in noncoaching activities (e.g., administrative assistants, academic counselors) do not count in the institution's coaching limitations, provided such individuals are not identified as coaches, do not engage in any on- or off-field coaching activities (e.g., attending meetings involving coaching activities, analyzing video involving the institution's or an opponent's team), and are not involved in any off-campus recruitment of prospective student-athletes or scouting of opponents.

3. NCAA Division I Bylaw 11.7.1.1.1.1.1 Exception -- Noncoaching Staff Member with SportSpecific Responsibilities. A noncoaching staff member with sport-specific responsibilities (e.g., director of operations, administrative assistant) may participate in organized activities involving only the coaching staff or may perform administrative duties (e.g., attend meetings involving coaching activities, analyze video of the institution's or an opponent's team, track statistics during practice or competition). However, such an individual is prohibited from participating in instructional activities with student-athletes and any on-court or on-field activities (e.g., assist with drills, throw batting practice), and is prohibited from participating with or observing student-athletes in the staff member's sport who are engaged in nonorganized voluntary athletically related activities (e.g., pick-up games).

4. NCAA Division I Interpretation (2003). Sports Psychologist/Use of Outside Consultants (I). It is permissible for an institution's athletics department to employ a sports psychologist without including such an individual in the institution's coaching limitations in a particular sport, provided the individual does not engage in any on- or off-field coaching activities (e.g., 
use equipment, review game films, set-up offensive or defensive alignments when meeting with the student-athletes, meetings involving coaching activities). A sports psychologist may engage in "mental imaging" with a student-athlete without being considered a countable coach, provided no coaching activities occur; however, if a student-athlete is required to meet with the sports psychologist, such a meeting is considered a countable athletically related activity.

5. NCAA Division I Interpretation (2003). Sports Psychologist Attending Practice Sessions. It is permissible for a sports psychologist to attend practice sessions without including such an individual in the institution's coaching limitations, provided the individual does not participate in any coaching activities. The sports psychologist may evaluate a student-athlete during a practice session only for the purposes of assisting the student-athlete in off-court or off-field noncoaching activities (e.g., mental imagery) directly related to the sport.

6. NCAA Division I Bylaw 11.7.1.1.1.4 Use of Outside Consultants. An institution may use or arrange for a temporary consultant to provide in-service training for the coaching staff, but no interaction with student-athletes is permitted unless the individual is counted against the applicable coaching limits. An outside consultant may not be involved in any on- or off-field or on- or off-court coaching activities (e.g., attending practices and meetings involving coaching activities, formulating game plans, analyzing video involving the institution's or opponent's team) without counting the consultant in the coaching limitations in that sport.

\section{References}

Bemiller, J.H. \& Wrisberg, C.A. (2011). An Overview and Critique of NCAA Policy Regarding the Use of Sport Psychology Consultants at the Division I Level. Journal of Intercollegiate Sport. December 2011.

Harmon, K.G., Asif, I.M., Klossner, D., \& Drezner, J.A. (2011). Incidence of Sudden Cardiac Death in National Collegiate Athletic Association Athletes. Circulation, 1594-1600.

Hosick, M. B. (2005). Psychology of sport more than performance enhancement. The NCAA News. Indianapolis, IN: The National Collegiate Athletic Association (NCAA).

NCAA Legislative Services Database-LSDBi [Computer Software]. (2011) Indianapolis, IN: The National Collegiate Athletic Association (NCAA).

NCAA Legislative Services Database-LSDBi [Computer Software]. (2010). Educational Column: Limitations on the Number and Duties of Coaches -- Responsibilities of Noncoaching Staff Members and Managers. Indianapolis, IN: The National Collegiate Athletic Association (NCAA).

NCAA Sports Medicine Handbook. Depression: Intervention for Intercollegiate Athletics (2006). Indianapolis, IN: The National Collegiate Athletic Association (NCAA).

Thompson, R.A. \& Sherman, R.T. (2007). Managing Student-Athletes' Mental Health Issues. Indianapolis, IN: The National Collegiate Athletic Association (NCAA). 